\title{
Supporting Information: Fighting Health Hazards in Lead Halide Perovskite Optoelectronic Devices with Transparent Phosphate Salts
}

Endre Horváth $^{1,2 *}$, Marton Kollár ${ }^{1 *}$, Pavao Andričević ${ }^{1}$, Lidia Rossi ${ }^{1}$, Xavier Mettan ${ }^{1}$, and László Forró ${ }^{1}$

${ }^{1}$ Laboratory of Physics of Complex Matter, École Polytechnique Fédérale de Lausanne (EPFL), 1015 Lausanne, Switzerland

${ }^{2}$ Institute for Industrial Sciences and Technologies, HEPIA-HES-SO, 1202 Geneva, Switzerland

Corresponding author: endre.horvath@epfl.ch 
Possible reactions for the lead ion immobilization:

Main reaction in water:

$2 \mathrm{CH}_{3} \mathrm{NH}_{3} \mathrm{PbI}_{3}+\left(\mathrm{NH}_{4}\right)_{2} \mathrm{HPO}_{4}+\mathrm{H} 2 \mathrm{O} \rightarrow \mathrm{Pb}_{2} \mathrm{PO}_{4} \mathrm{I}+2 \mathrm{CH}_{3} \mathrm{NH}_{3} \mathrm{I}+2 \mathrm{NH}_{4} \mathrm{I}+\mathrm{HI}$

Further reactions:

$5 \mathrm{CH}_{3} \mathrm{NH}_{3} \mathrm{PbI}_{3}+3\left(\mathrm{NH}_{4}\right)_{2} \mathrm{HPO}_{4} \rightarrow \mathrm{Pb}_{5}\left(\mathrm{PO}_{4}\right)_{3} \mathrm{I}+6\left(\mathrm{NH}_{4}\right) \mathrm{I}+5 \mathrm{CH}_{3} \mathrm{NH}_{3} \mathrm{I}+3 \mathrm{HI}$

$\mathrm{CH}_{3} \mathrm{NH}_{3} \mathrm{PbI}_{3}+\left(\mathrm{NH}_{4}\right)_{2} \mathrm{HPO}_{4} \rightarrow \mathrm{PbHPO}_{4}+2\left(\mathrm{NH}_{4}\right) \mathrm{I}+\mathrm{CH}_{3} \mathrm{NH}_{3} \mathrm{I}$

$\mathrm{CH}_{3} \mathrm{NH}_{3} \mathrm{PbI}_{3}+\mathrm{H}_{2} \mathrm{O} \leftrightarrow \mathrm{PbI}_{2}+\mathrm{CH}_{3} \mathrm{NH}_{3} \mathrm{I}$ (aq.)

$\mathrm{CH}_{3} \mathrm{NH}_{3} \mathrm{I}$ (aq.) $\leftrightarrow \mathrm{CH}_{3} \mathrm{NH}_{2}$ (aq.) $+\mathrm{HI}$ (aq.)

$4 \mathrm{HI}$ (aq.) $+\mathrm{O}_{2} \leftrightarrow 2 \mathrm{I}_{2}+2 \mathrm{H}_{2} \mathrm{O}$

$2 \mathrm{HI}($ aq. $) \leftrightarrow \mathrm{H}_{2}+\mathrm{I}_{2}$

Reactions of $\mathrm{CH}_{3} \mathrm{NH}_{3} \mathrm{PbCl}_{3}$ and $\mathrm{CH}_{3} \mathrm{NH}_{3} \mathrm{PbBr}_{3}$ with $\left(\mathrm{NH}_{4}\right)_{2} \mathrm{HPO}_{4}$ in the presence of water:

$5 \mathrm{CH}_{3} \mathrm{NH}_{3} \mathrm{PbCl}_{3}+3\left(\mathrm{NH}_{4}\right)_{2} \mathrm{HPO}_{4} \rightarrow \mathrm{Pb}_{5}\left(\mathrm{PO}_{4}\right)_{3} \mathrm{Cl}+6\left(\mathrm{NH}_{4}\right) \mathrm{Cl}+5 \mathrm{CH}_{3} \mathrm{NH}_{3} \mathrm{Cl}+3 \mathrm{HCl}$

$5 \mathrm{CH}_{3} \mathrm{NH}_{3} \mathrm{PbBr}_{3}+3\left(\mathrm{NH}_{4}\right)_{2} \mathrm{HPO}_{4} \rightarrow \mathrm{Pb}_{5}\left(\mathrm{PO}_{4}\right)_{3} \mathrm{Br}+6\left(\mathrm{NH}_{4}\right) \mathrm{Br}+5 \mathrm{CH}_{3} \mathrm{NH}_{3} \mathrm{Br}+3 \mathrm{HBr}$ 


\begin{tabular}{|c|c|c|}
\hline Chemical formula & Name & $\mathrm{K}_{\mathrm{SP}}\left(25^{\circ} \mathrm{C}\right)$ \\
\hline$\overline{\mathbf{P b S}}$ & "Lead sulfide & $9.04 \times 10^{-29}$ \\
\hline $\mathrm{PbSO}_{4}$ & Lead sulphate & $1.82 \times 10^{-8}$ \\
\hline $\mathrm{Pb}(\mathrm{OH})_{2}$ & Lead hydroxide & $1.42 \times 10^{-20}$ \\
\hline $\mathrm{Pb}_{3}\left(\mathrm{PO}_{4}\right)_{2}$ & Lead orthophosphate & $10^{-44.4}$ \\
\hline $\mathrm{PbHPO}_{4}$ & Lead phosphate & $10^{-11.43}$ \\
\hline $\mathbf{P b I}_{2}$ & Lead iodide & $8.49 \times 10^{-9}$ \\
\hline $\mathrm{Pb}(\mathbf{a c})_{2}$ & Lead acetate & Water soluble \\
\hline $\mathrm{PbBr}_{2}$ & Lead bromide & $6.60 \times 10^{-6}$ \\
\hline $\mathrm{PbCO}_{3}$ & Lead carbonate & $1.46 \times 10^{-13}$ \\
\hline $\mathbf{P b C l}_{2}$ & Lead chloride & $1.17 \times 10^{-5}$ \\
\hline $\mathrm{Pb}_{5}\left(\mathrm{PO}_{4}\right)_{3} \mathrm{OH}$ & Hydroxypyromorphite & $10^{-76.8}$ \\
\hline $\mathrm{Pb}_{5}\left(\mathrm{PO}_{4}\right)_{3} \mathrm{Cl}$ & Chloropyromorphite & $10^{-84.4}$ \\
\hline $\mathrm{Pb}_{5}\left(\mathrm{PO}_{4}\right)_{3} \mathrm{~F}$ & Fluropyromorphite & $10^{-71.6}$ \\
\hline $\mathrm{Pb}_{5}\left(\mathrm{PO}_{4}\right)_{3} \mathrm{Br}$ & Bromopyromorphite & $10^{-78.1}$ \\
\hline
\end{tabular}

Table S1 Solubility data of the most common lead-containing compounds. Sources: Handbook of Inorganic Chemicals by Pradyot Patnaik ISBN 0-07-049439-8 and Handbook or Inorganic Compounds $\left(2^{\text {nd }}\right.$ Edition) by Dale L. Perry ISBN: 978-1-4398-1461-1 

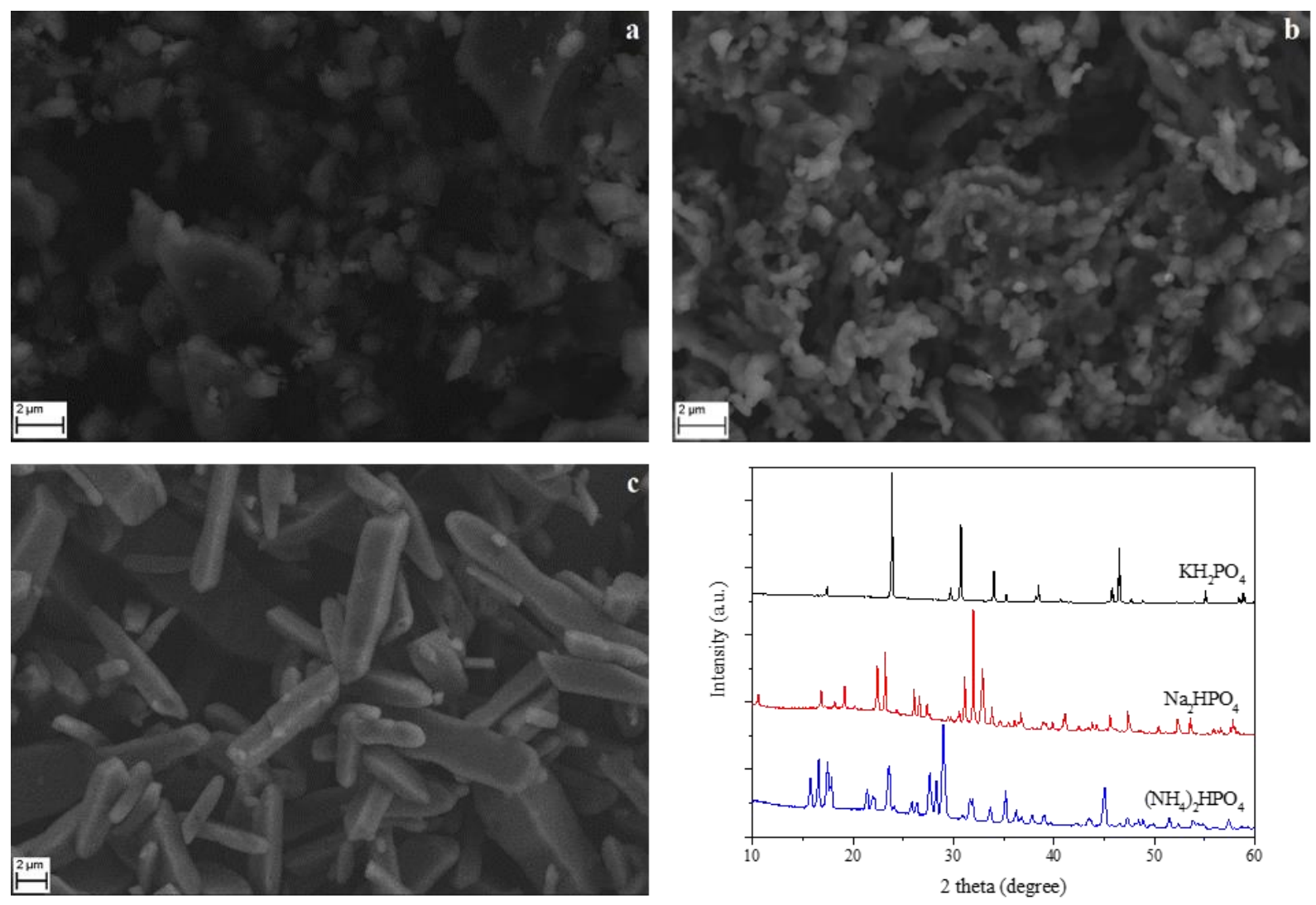

Figure S1. Scanning electron microscopy images of micro-crystallized phosphate salts. SEM images $\left(\mathrm{NH}_{4}\right)_{2} \mathrm{HPO}_{4}(\mathrm{a}), \mathrm{Na}_{2} \mathrm{HPO}_{4}(\mathrm{~b}), \mathrm{KH}_{2} \mathrm{PO}_{4}(\mathrm{c})$, and their $\mathrm{X}$-ray patterns. The microcrystals were made by precipitation of the concentrated solutions of the salts in acetone, followed by a drying step. 

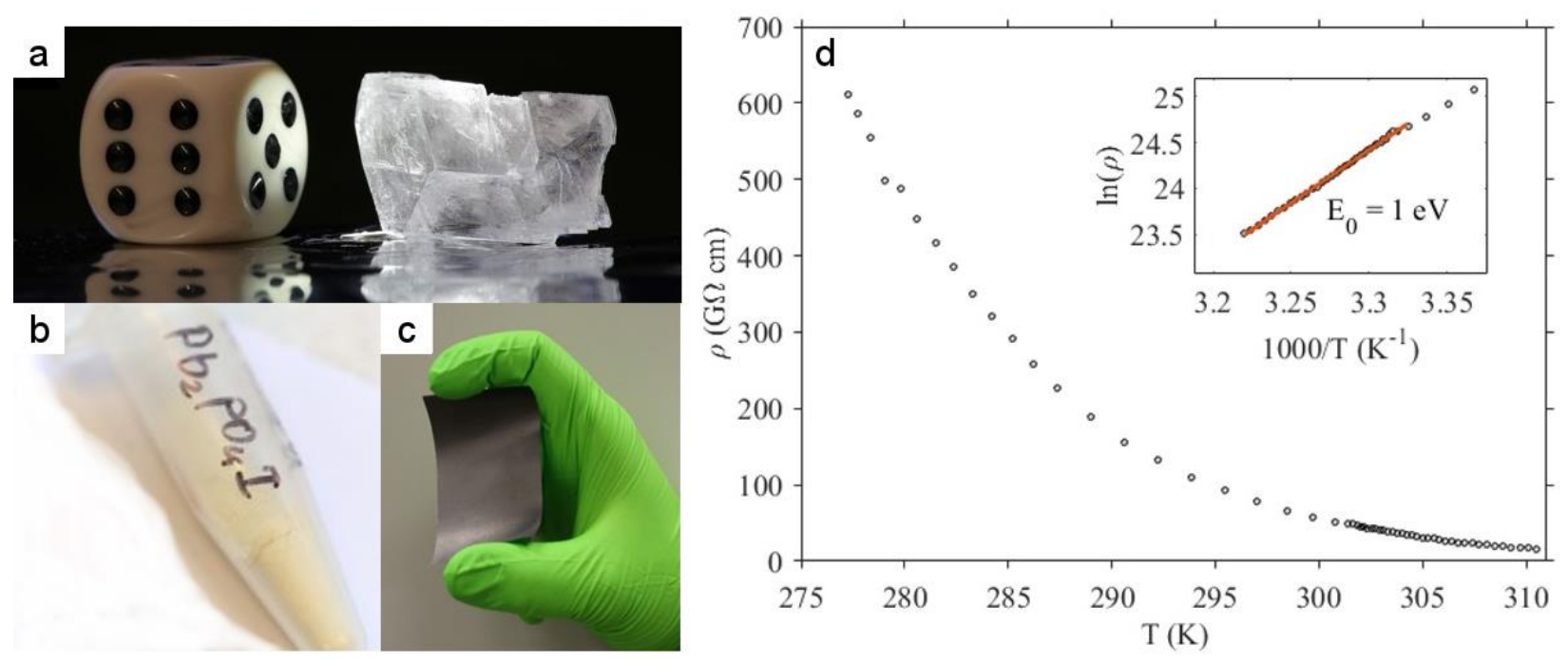

Figure S2. Images of DAP single crystals, $\mathrm{Pb}_{2} P \mathrm{O}_{4} I$ and the back electrode. Pictures were taken of a (a) $D A P$ transparent single crystal and $(b)$ of the $\mathrm{Pb}_{2} \mathrm{PO}_{4} I$ powder made by the reaction of $M A P b I_{3}$ and $D A P$ in the presence of water. (c) Back electrode of a flexible photodetector device. The composition is Al foil, a thin film of DAP mixture and electrically conductive graphite spray layer on the top.(d) Resistivity graph for the DAP single crystal. 
$\mathrm{CH}_{3} \mathrm{NH}_{3} \mathrm{PbCl}_{3}$ reaction with $\left(\mathrm{NH}_{4}\right)_{2} \mathrm{HPO}_{4}$ in the presence of water

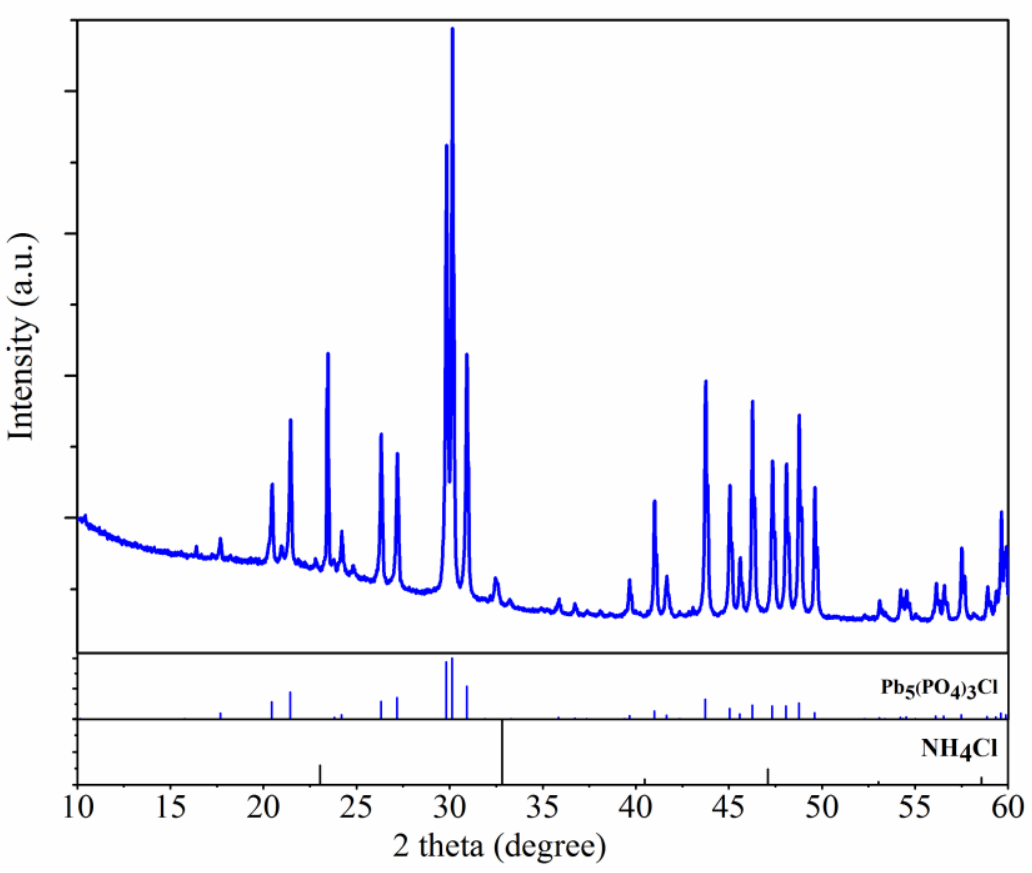

$\mathrm{CH}_{3} \mathrm{NH}_{3} \mathrm{PbBr}_{3}$ reaction with $\left(\mathrm{NH}_{4}\right)_{2} \mathrm{HPO}_{4}$ in the presence of water

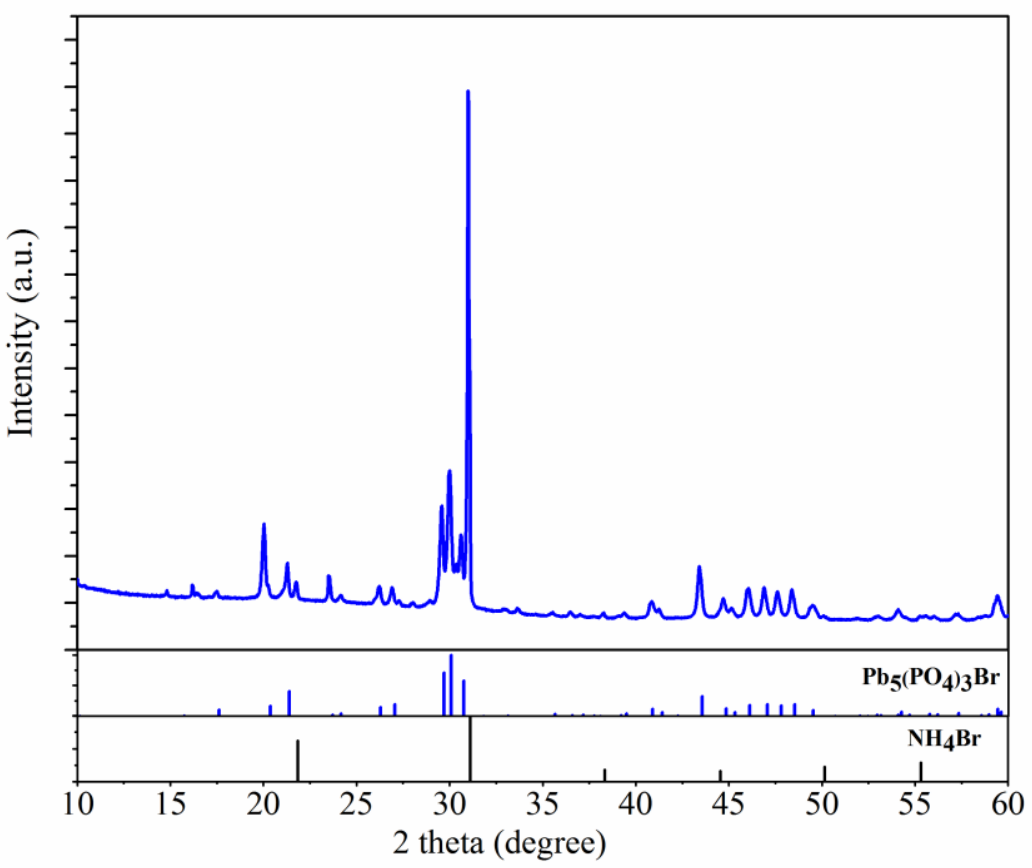

Figure S3. XRD patterns of the products formed by the reaction of $\mathrm{CH}_{3} \mathrm{NH}_{3} \mathrm{PbCl}_{3}$ and $\mathrm{CH}_{3} \mathrm{NH}_{3} \mathrm{PbBr}_{3}$ with the double molar amount of $\left(\mathrm{NH}_{4}\right)_{2} \mathrm{HPO}_{4}$ in the presence of water. The identified phases are $\mathrm{Pb}_{5}\left(\mathrm{PO}_{4}\right)_{3} \mathrm{Cl}$ and $\mathrm{Pb}_{5}\left(\mathrm{PO}_{4}\right)_{3} \mathrm{Br}$ in the case of $\mathrm{CH}_{3} \mathrm{NH}_{3} \mathrm{PbCl}_{3}$ and $\mathrm{CH}_{3} \mathrm{NH}_{3} \mathrm{PbBr}_{3}$, respectively. 

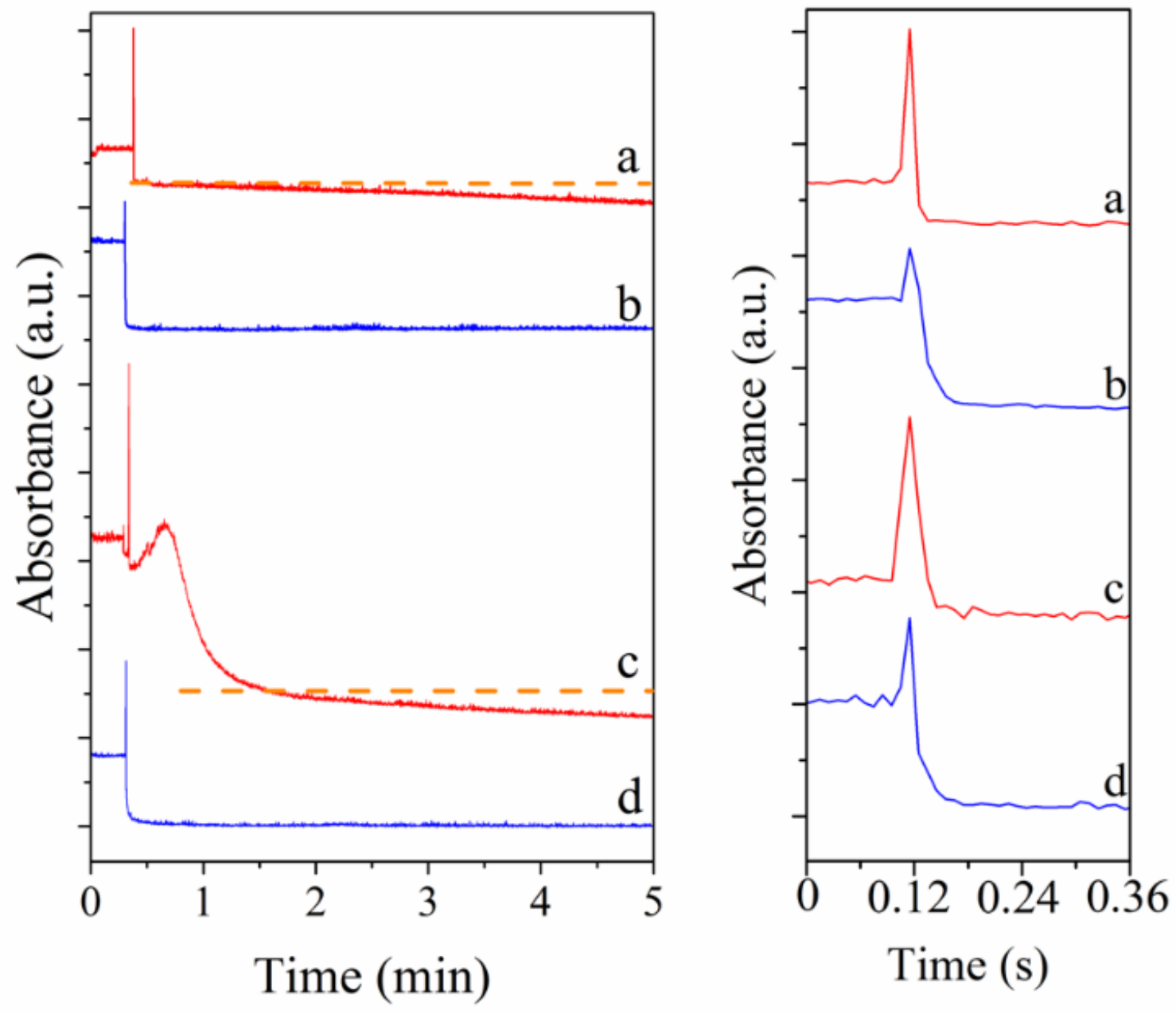

Figure S4. The transformation of $\mathrm{MAPbI}_{3}$ and $\mathrm{PbI}_{2}$ followed by $\mathrm{UV}$-Vis spectrometry at $450 \mathrm{~nm}$. The reaction of $\mathrm{MAPbI}_{3}$ film with water (a) and with $\left(\mathrm{NH}_{4}\right)_{2} \mathrm{HPO}_{4}(b)$ and the reaction of $\mathrm{PbI}_{2}$ film with water (c) and with $\left(\mathrm{NH}_{4}\right)_{2} \mathrm{HPO}_{4}(d)$. The reaction is continuous with water $(a, c)$ and immediate with the phosphate solution $(b, d)$. 

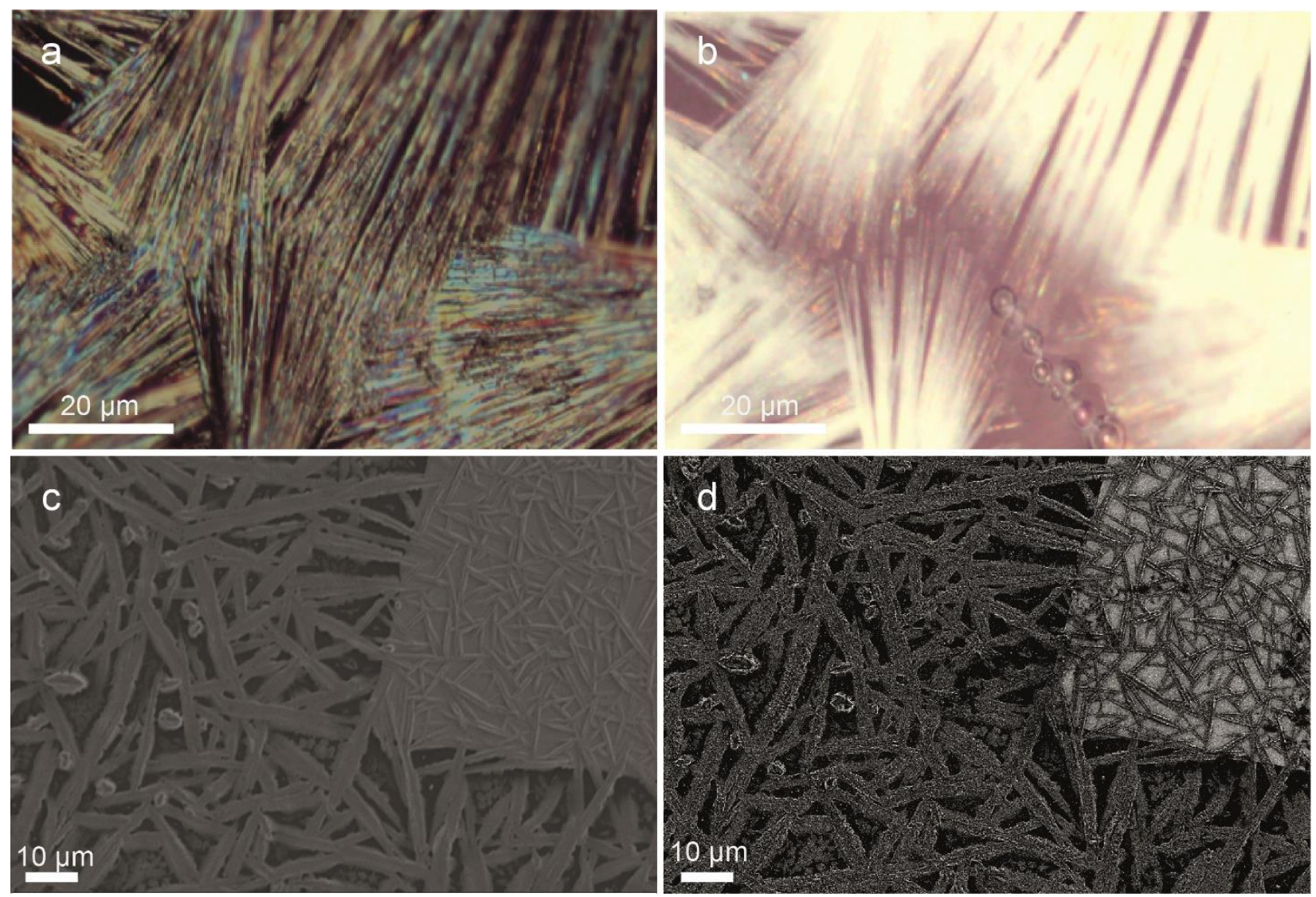

Figure S5. Texture change during the formation of the insoluble lead compound. Optical microscope images of $\mathrm{CH}_{3} \mathrm{NH}_{3} \mathrm{PbI}_{3}$ nanowires (a), after the reaction with $\left(\mathrm{NH}_{4}\right)_{2} \mathrm{HPO}_{4}$ in water solution and the formed $\mathrm{Pb}_{2} \mathrm{PO}_{4} \mathrm{I}$ wires. SEM micrographs of $\mathrm{MAPbI}_{3}$ nanowires before (c) and after (d) the reaction with $\left(\mathrm{NH}_{4}\right)_{2} \mathrm{HPO}_{4}$ in water solution.

Having obtained evidence about the high-speed lead iodophosphate precipitate formation, we were interested in investigating the recrystallization mechanism at a microscopic level. Optical microscope (SI. Fig. 5a, b), scanning electron microscope (SEM) (SI. Fig. 5c, d) were recorded for comparison before and after the transformation of $\mathrm{MAPbI}_{3}$ wires. The lead iodophosphate crystals preserve the needle-like shape (SI. Fig 5c) of the original $\mathrm{CH}_{3} \mathrm{NH}_{3} \mathrm{PbI}_{3}$ crystals perfectly (SI. Fig 5d). XRD and TEM measurements confirmed the composition of the formed $\mathrm{Pb}_{2} \mathrm{PO}_{4} \mathrm{I}$ needles. 

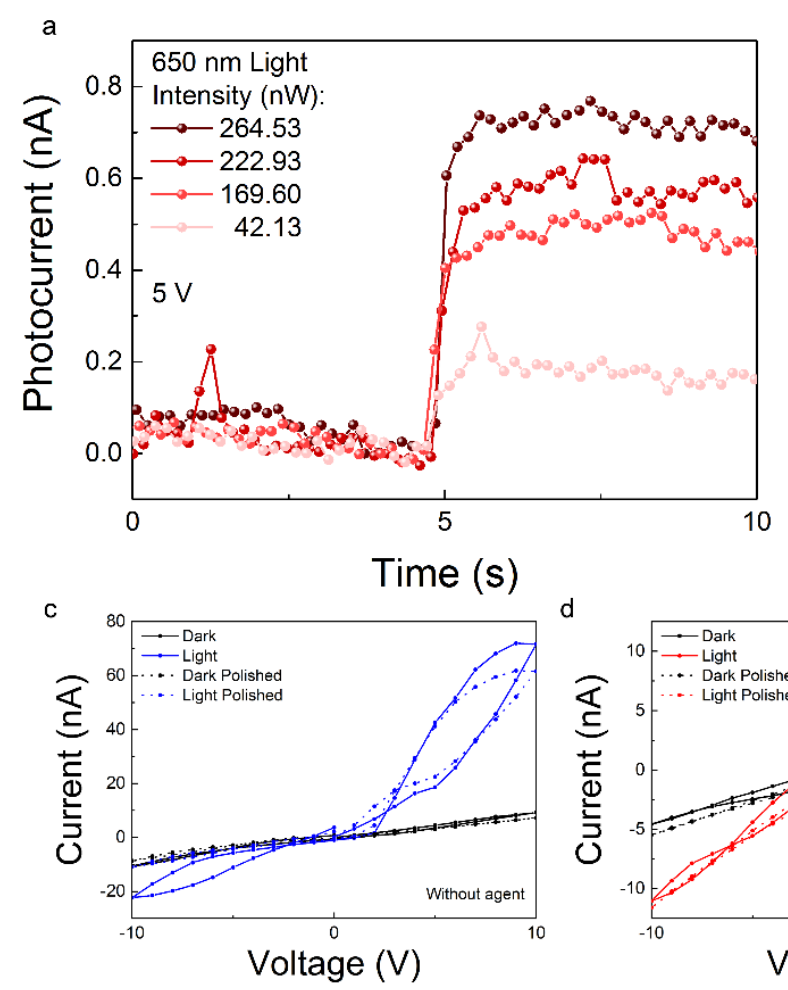
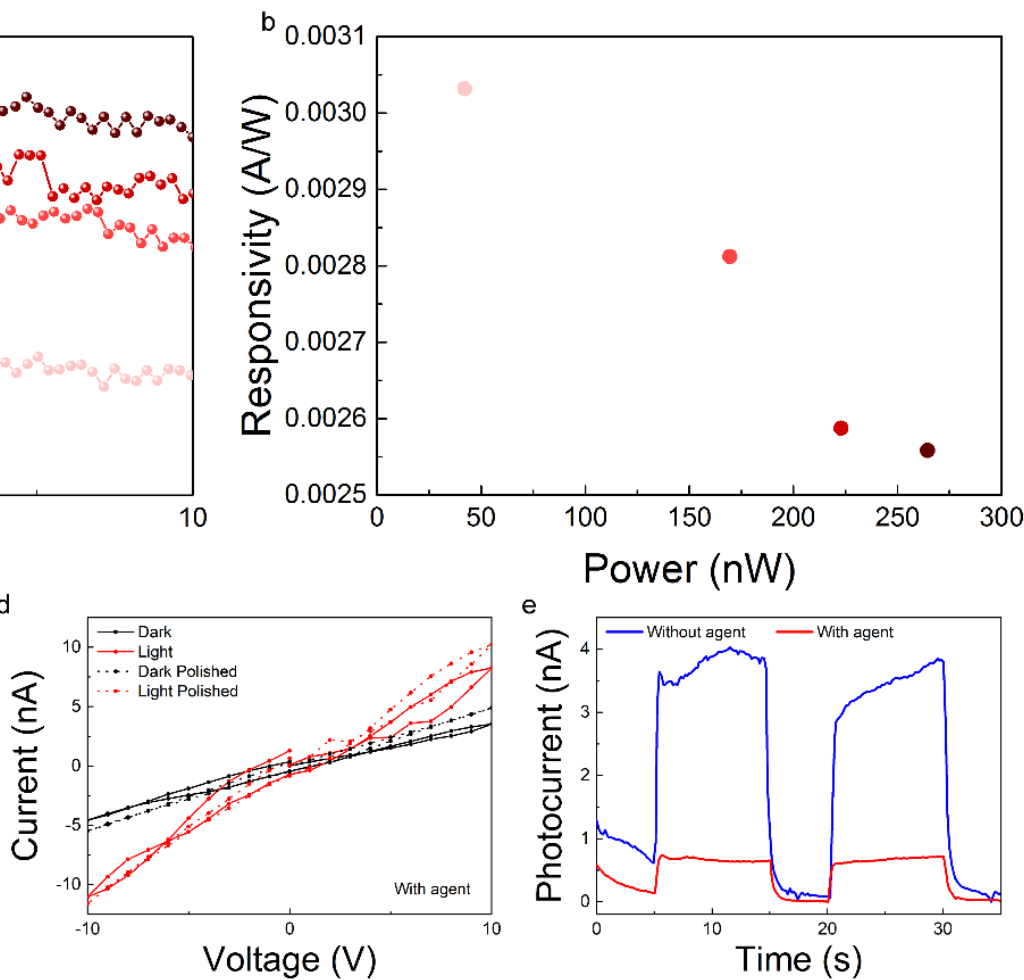

Figure S6. I-V curves and on-off graphs of the $\mathrm{MAPbI}_{3}$ and the MAPbI${ }_{3}+$ DAP pressed pellet. (a) Photoresponse edge of the photodetector under white light illumination of different intensities (42, 170, 223, $265 \mathrm{nW}$ ). (b) Calculated responsivity in dependence of the illumination power. I-V curves of the photodetector in the dark and under white light illumination $(c)$ with and $(d)$ without the DAP agent. (e) Comparison of on-off photoresponse measurements with and without the DAP agent under a $5 \mathrm{~V}$ bias voltage.

I-V photocurrent characteristics of the device were obtained under the illumination of a white fluorescent light source with different intensities (42, 170, 223 and $265 \mathrm{nW})$ at ambient conditions. As can be seen in SI Figure 6c, the perovskite device reveals diode-like behaviour, however detecting like in both forward and reverse bias direction. Interestingly, a finite photocurrent was detected when no bias voltage is applied (SI Figure 6d). Furthermore, measurements of the photocurrent at ambient condition were done under low light intensities to determine the responsivity of the device. On-off measurements were performed for light intensities ranging from 42 to $265 \mathrm{nW}$. The corresponding on-off characteristics of the transient photoresponse collected at $5 \mathrm{~V}$ are shown in Figure 6e. From these results, the responsivity $\mathrm{R}$ of the device can be calculated. $\mathrm{R}$ is defined as the ratio of the photocurrent and the intensity of light. The responsivity of the device is in the order of magnitude of $10^{-3} \mathrm{~A} / \mathrm{W}$ and increases with lower intensities of light.

To determine the impact of DAP on photoelectric properties of LAMI, powdered $\mathrm{MAPbI}_{3}$ was mixed with microcrystalline DAP and $\mathrm{NH}_{4} \mathrm{H}_{2} \mathrm{PO}_{4}$ in an agate mortar. The mixed pellet shows electronic properties similar to the pure $\mathrm{MAPbI}_{3}$ both under the light on and off conditions, albeit with fewer intensities. 

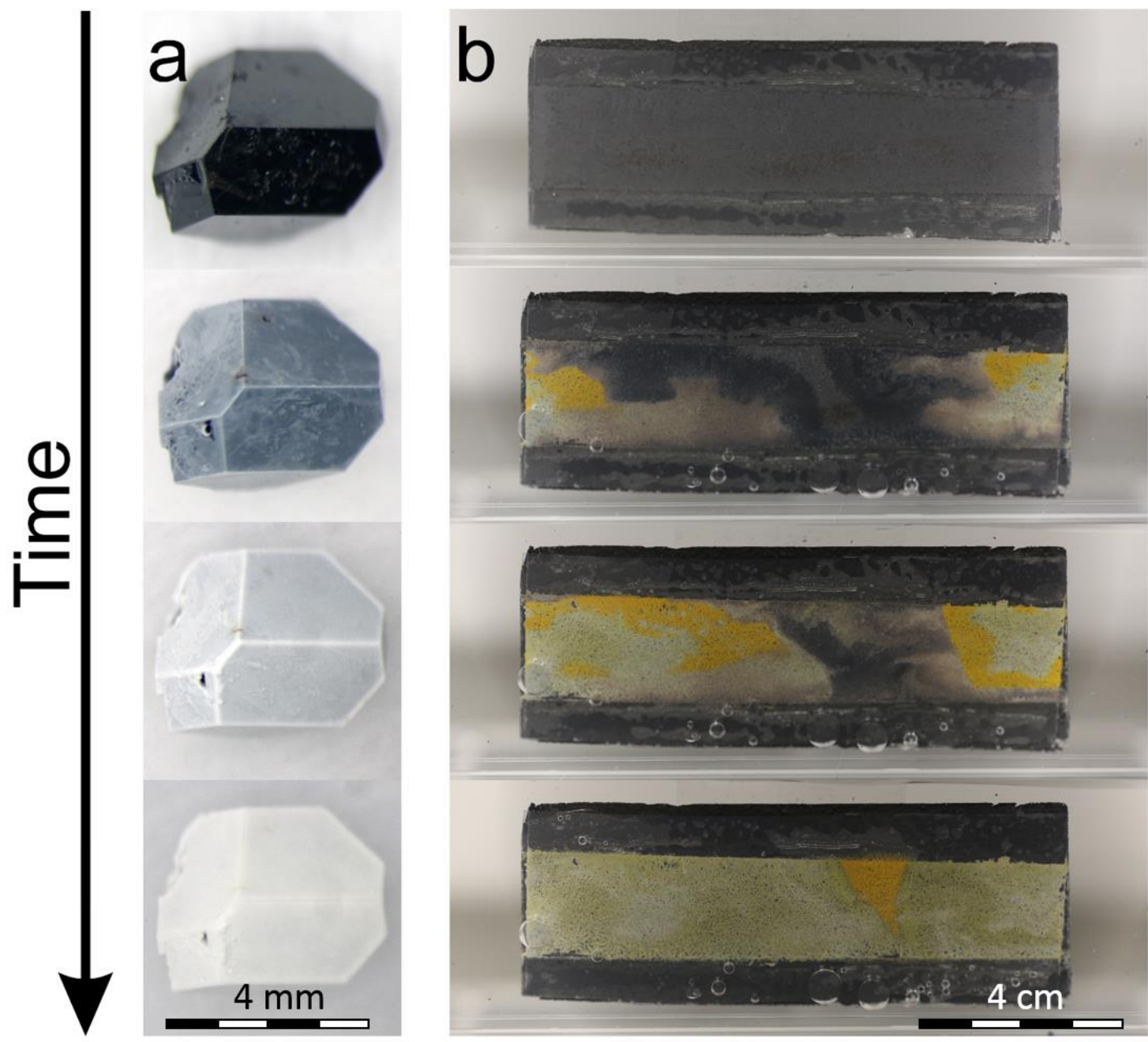

Figure S7. Formation of the insoluble lead compound. Optical microscope images of the formation of insoluble, white $\mathrm{Pb}_{2} \mathrm{PO}_{4} \mathrm{I}$ compound from $\mathrm{MAPbI}_{3}$ single crystal (a), and degradation of a DAP containing $M A P b I_{3}$ photodetector (b) immersed into water. 


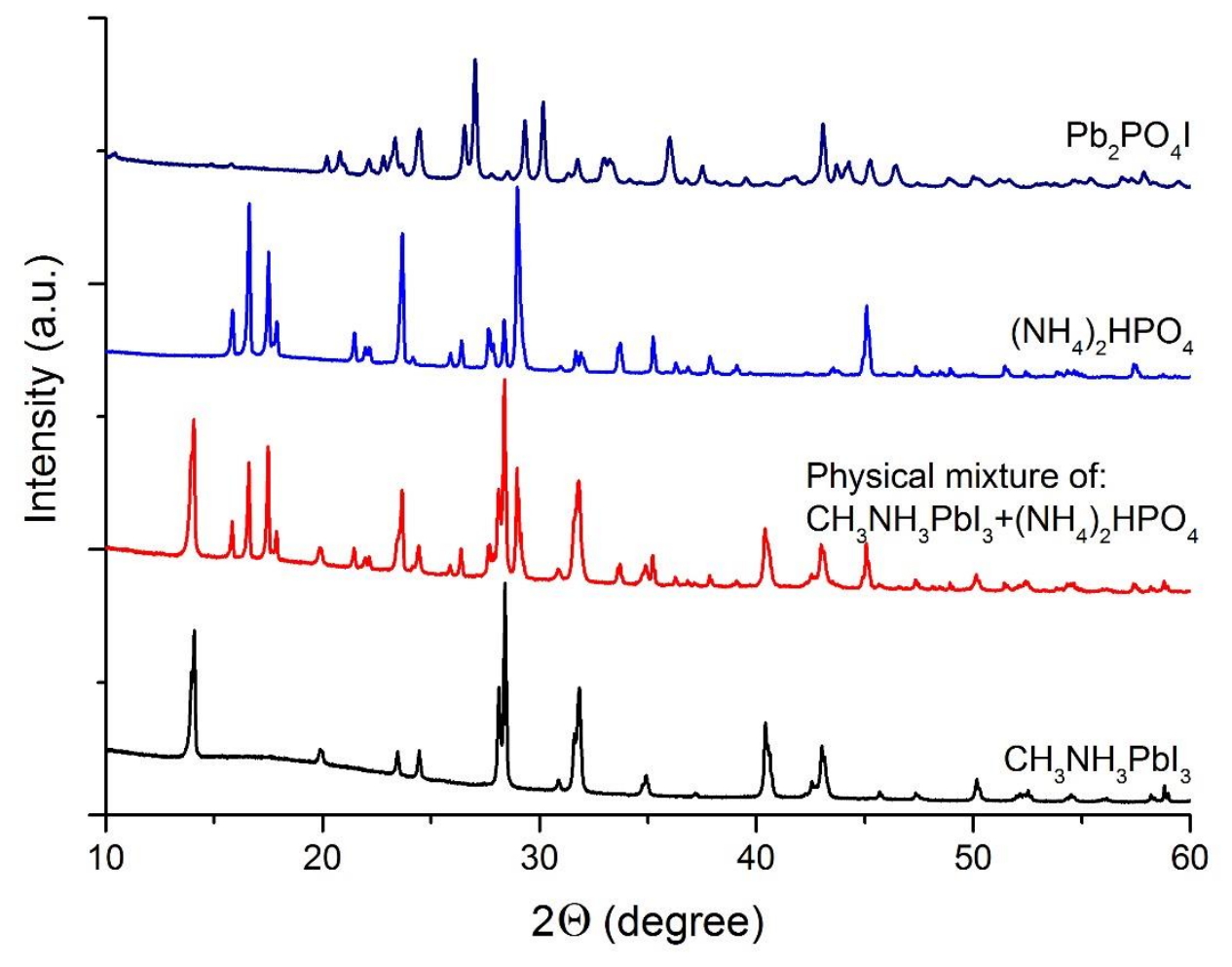

Figure S8. XRD pattern of the physical mixture of $\mathrm{MAPbI}_{3}$ and DAP. In a dry environment, the MAPbI doesn't react with the phosphate salt. The red coloured pattern of the physical mixture depicts only the characteristic diffraction peaks of the $\mathrm{MAPbI}_{3}$ and the $\left(\mathrm{NH}_{4}\right)_{2} \mathrm{HPO}_{4}$ and the absence of the characteristic diffraction peaks of potential reaction products such as $\mathrm{PbI} 2$ or $\mathrm{PbPO}_{4} \mathrm{I}$ is visible. 